\title{
Hydrological model for Hemren dam reservoir catchment area at the middle River Diyala reach in Iraq using ArcSWAT model
}

\author{
Thair Sharif Khayyun ${ }^{1} \cdot$ Imzahim Abdulkareem Alwan ${ }^{1}$. Ali Mohsen Hayder ${ }^{2}$
}

Received: 7 December 2018 / Accepted: 24 June 2019 / Published online: 5 July 2019

(c) The Author(s) 2019

\begin{abstract}
In this study, the catchment area's runoff of Hemren dam reservoir within middle River Diyala reach beyond DerbendiKhan dam at the northeast of Iraq is simulated using the Soil Water Assessment Tool (ArcSWAT-2012) model integrated with remote sensing and geographical information systems. The model was calibrated in monthly time step for the period extended from 1981 to 2000 with 2 years of warm-up period and validated with observed stream flow for years between 2001 and 2008. The model calibration and parameters sensitivity analysis were conducted using automatic calibration method within the SWAT-CUP program. The model performance for the studied catchment area was evaluated with many statistical criteria. In general, the performance of the model was good. Results of sensitivity analysis showed that there are seven parameters that mostly effect on the hydrological processes in the studied catchment; these were ALPHA_BF, CH_K2, CN2, CH_N2, SOL_AWC, REVAPMN, and GW_REVAP. Results showed that an effective runoff happens at wet seasons, and there is not continuous effective base flow from the studied catchment, and the average annual inflow volume to Hemren dam reservoir during the simulation period was $0.871 \mathrm{BCM}$, i.e., $17.42 \%$ of the overall inflow volume to Hemren dam reservoir. Furthermore, it was founded that the use of climate forecast system reanalysis of global weather station data is possible in the studied catchment area. Finally, a simple direct regression formula is determined by correlating the monthly runoff volume with monthly rainfall depth.
\end{abstract}

Keywords ArcSWAT model $\cdot$ Hemren dam $\cdot$ Runoff $\cdot$ Rainfall depth

\section{Introduction}

Hydrological modelling is making simpler of the conceptual representation of a part of the hydrology cycle, and it is fundamentally used to describe the physical processes in a watershed that controls the conversion of precipitation to runoff. The watershed is the entrance step that acts as a beginning for addressing issues regarding sustainable water resources management beneficently. To deal with water

Thair Sharif Khayyun

thshkhma@yahoo.com

Imzahim Abdulkareem Alwan

mzahim74@gmail.com

Ali Mohsen Hayder

Alim.albayati@uokufa.edu.iq

1 Civil Engineering Department, University of Technology, Baghdad, Iraq

2 Faculty of Engineering, University of Kufa, An Najaf, Iraq resources management issues, the different hydrological processes elements that are taking place within the watershed should be analyzed and quantified. Undoubtedly, the watershed must be the basis of this analysis that carries out because all these hydrological processes are occurring inside individual micro-watersheds. Subsequently, when the spatial and temporal variation and the interaction of hydrological processes components are understood, then the strategies of runoff and soil conservation can scientifically be formulated. Recently, there are different hydrologic models that are created with various structural characteristics. Many researchers categorized these models based on their visions and objectives, for instance as in Chow et al. (1988) and Elizabeth (1994). Thus, several purposes can be served with hydrological models as in Todini (2007), where the decisions that regard to water resources management are directly impacted by the accuracy and skill of streamflow prediction models. Several conceptual and statistical watershed runoff prediction models have been developed to help policy 
makers, urban planners, and administrators make better and more informed decisions as in Noori and Kalin (2016).

Among the different kinds of models, semi-distributed models are the most efficient model for hydrological simulation as it exceeds the difficulties normally faced with fully distributed model and lumped model (Jajarmizadeh et al. 2013). Out of these models, the Soil and Water Assessment Tool (SWAT) is a continuous daily step, long period, physically based parameter, and distributed hydrologic model has been used widely to simulate agricultural watersheds management practices as in Moriasi et al. (2011), help to evaluate the climate change impacts as in Singh and Gosain (2011), identify water quality in watersheds as in Boithias et al. (2011) and Oeurng et al. (2010), and assess the surface, subsurface flow, and sediment yield transfer in various watersheds with varying soils as in Arnold et al. (2012) and Gassman et al. (2014). Researchers have applied ArcSWAT model in several wet and semi-arid areas around the world, such as southern Australia as in Shrestha et al. (2016), South Asia as in Shivhare et al. (2014), North and southeast Africa as in Baker and Miller (2013), Bouraoui et al. (2005) and Sellami et al. (2016), and in the Mediterranean coastal basin in Spain as in Molina-Navarro et al. (2014). Several researchers have studied the water balance of the dam's reservoir watershed using SWAT model as in Neitsch et al. (2002, 2011), China as in Wang and Xia (2010) and Pakistan as in Ghoraba (2015).

The present study was undertaken on the application of the ArcSWAT model which is not widely used for watersheds in Iraq and integrates the geographical information systems (GIS) information with attribute database to estimate the runoff. Nowadays, Iraq suffers from water resources problems, because of the construction of a series of storage dams in the riparian countries (Turkey, Syria, and Iran) of both Tigris and Euphrates rivers, so the estimation and improving contribution of the runoff volume that stores Hemren dam reservoir are important for the prudent management of sustainable water resources. The model application has been demonstrated for the Hemren dam reservoir catchment area part of River Diyala watershed. Hence, the objectives of this study were: (1) to model hydrological processes of the middle River Diyala catchment in Iraq based on semi-distributed hydrological model ArcSWAT-2012; (2) to evaluate the contribution of the middle River Diyala catchment area to surface runoff that inters to Hemren dam reservoir regardless of the releases from the Derbendi-Khan dam; (3) to find a possibility to use the climate forecast system reanalysis (CFSR) of global weather station data.

\section{Study area}

The River Diyala, a tributary of River Tigris which originates from the northwest border of Iran and located within longitude $44^{\circ} 30^{\prime}-47^{\circ} 50^{\prime}$ and latitude $33^{\circ} 57^{\prime}-35^{\circ} 50^{\prime}$, is one of the important rivers in Iraq draining an area reaching $29,675.5 \mathrm{~km}^{2}$ up to Hemren dam site Fig. 1. Two dams have been constructed on the river, Derbendi-Khan dam which is

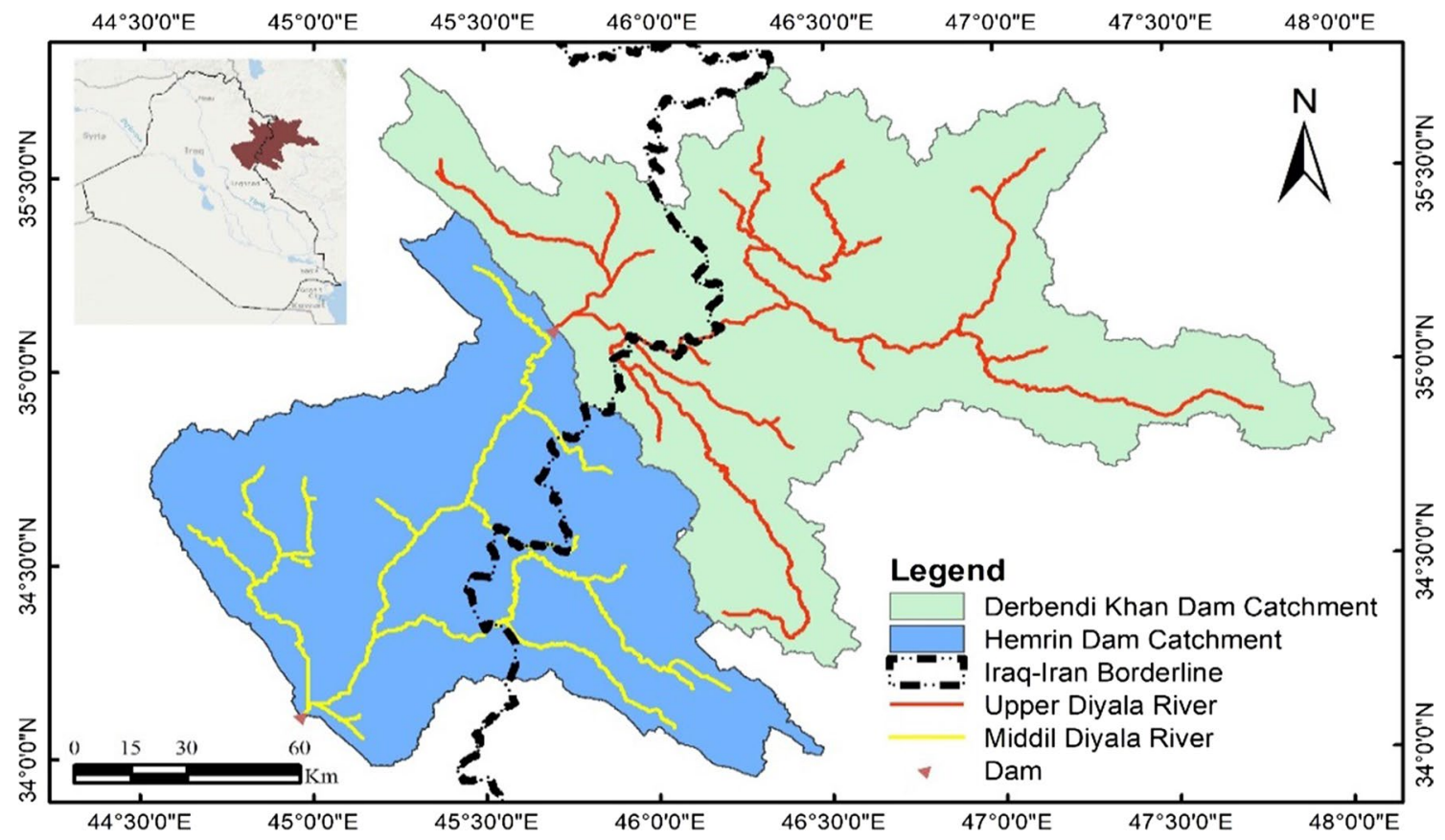

Fig. 1 Location of the studied catchment areas 
situated in the upper parts and Hemren dam which is located in the middle parts of the river catchment $(360$ and $188 \mathrm{~km}$ upstream the confluence with the Tigris River in south Baghdad, respectively) as in Al-Ansari et al. (1986). The data of an intermediate part of Diyala river watershed were used for assessment of runoff in the present study. Hemren dam reservoir catchment covers an area in northeast of Iraq distributed in three provinces of Diyala, Kirkuk, and Sulaymaniyah and northwest of Iran, the catchment area of Hemren dam drains an area of $12,930.17 \mathrm{~km}^{2}$ with $82 \%$ and $18 \%$ in Iraq and Iran, respectively, with an elevation between 73 and $2559 \mathrm{~m}$ above mean sea level. The catchment area is located between latitude $33^{\circ} 57^{\prime} 9^{\prime \prime}$ to $35^{\circ} 25^{\prime} 4^{\prime \prime} \mathrm{N}$ and longitude $44^{\circ} 31^{\prime} 15^{\prime \prime}$ to $46^{\circ} 28^{\prime} 24^{\prime \prime} \mathrm{E}$. On the northwest, it is bounded by the Adhaim dam river catchment, while on the northeast it is adjoined by the catchment of the Derbendi-Khan dam reservoir in which its release was taken as a source point of Hemren dam catchment, Fig. 1. Hemren dam was constructed between 1976 and 1981 near Al-Mansouryah town of Diyala province on the Diyala River, approximately $105 \mathrm{~km}$ northeast of Baghdad and $52 \mathrm{~km}$ northeast of Baqubah city, and its main purposes are flood control, irrigation, and hydroelectric generation. The hydrological records indicate that the mean monthly and yearly discharges for the period 1981-2008 reach 151 and $1814.4 \mathrm{~m}^{3} / \mathrm{s}$, respectively, while the maximum and minimum mean monthly and yearly discharges were 1209 and 0,4593 and $456 \mathrm{~m}^{3} / \mathrm{s}$, respectively, and the most peak flows occur at March and April. Also, for this period, the annual precipitation ranged between $171 \mathrm{~mm}$ and $413 \mathrm{~mm}$. Hemren dam reservoir fed by the rainfall during the wet seasons, groundwater flow, snowmelt, and by releases from Derbendi-Khan dam reservoir.

\section{Model description and methodology}

\section{SWAT model}

The SWAT is a continuous, long period, physically distributed parameter model that can simulate surface and subsurface flow, sediment yield, and water quality of agricultural watersheds as in Arnold et al. (1998). It is used worldwide for evaluation of water balance allocation and climatic changes of the watershed. The major advantage of the model is it can be used for exploring the impact of land management practices with relative impacts of scenarios on runoff and eroded sediment yields from the watershed. This can also be applied in large and additionally for complex watersheds of ungauged and semi-ungauged river basins with different soils, land use, and management conditions over significant period of time as in Neitsch et al. (2011). Furthermore, SWAT has a weather simulation model also that generates daily data for rainfall, relative humidity, solar radiation, temperature, and wind speed from the monthly average values variables of these data. This gives a helpful tool to fill in missing daily information in the watched records.

Hydrological processes in SWAT model that represents the components of the hydrology of circulation of the water system take different forms where water is circulated through the earth-ocean-atmosphere system. These forms are including evapotranspiration, interception, surface runoff, soil percolation, lateral flow, and ground water flow and additionally river routing processes. The computation of the physical components processes described by the SWAT can be classified into these major divisions: hydrology, weather, sediment movement, soil temperature, plant growth, pesticides, nutrients, and agricultural management. The simulations of each one of the above-mentioned components are explained by a small spatial unit of the model. In this spatial unit, various categories of storage volumes are calculated, namely canopy storage, soil profile, shallow aquifer what is more, deep aquifer, and open channels. Computation of stream flow in the main channel is made up of surface runoff, lateral surface flow, and base flow. Figure 2 illustrates a schematization of the flow components of the earthen part of the hydrology cycle in which the major purposes of the hydrological modelling are to explore a part of the hydrological cycle, for example, the land phase of the hydrological cycle on a watershed, and this can control the amount of water, sediment yield, pesticide and nutrient that load into the main channel in each subbasin as in Arnold et al. (1998).

The fundamental simulation of the land phase hydrological cycle mechanism in the SWAT model is examined with the assistance of the water balance equation which is represented in Eq. (1):

$\mathrm{SW}_{t}=\mathrm{SW}_{0}+\sum_{i=1}^{n}\left(R_{\text {day }}-Q_{\text {suf }}-E_{\mathrm{a}}-W_{\text {seep }}-Q_{\mathrm{gw}}\right)$

where $\mathrm{SW}_{t}$ is the final soil water content $(\mathrm{mm}), \mathrm{SW}_{o}$ is the initial soil water content $(\mathrm{mm}), t$ is time in days, $R_{\text {day }}$ is amount of precipitation on day $i(\mathrm{~mm}), Q_{\text {surf }}$ is the amount of surface runoff on day $i(\mathrm{~mm}), E_{\mathrm{a}}$ is the amount of evapotranspiration on day $i(\mathrm{~mm}), w_{\text {seep }}$ is the amount of percolation and bypass exiting the soil profile bottom on day $i(\mathrm{~mm})$, $Q_{\mathrm{gw}}$ is the amount of return flow on day $i(\mathrm{~mm})$.

In SWAT model, the impact of spatial varieties in topography, soil, land use, and physical characteristics of the watershed is considered in subdivisions. In general, there are two levels of subdivision in the SWAT model for simulation of flow routing. The first is the watershed that is divided into a number of subbasins based on drainage areas of streams made by automatic digital elevation model (DEM)-based or user specified. The second is that each one of subbasins of the watershed is further subdivided into a number of smallest 
Fig. 2 Schematic representation of the hydrologic cycle in SWAT model

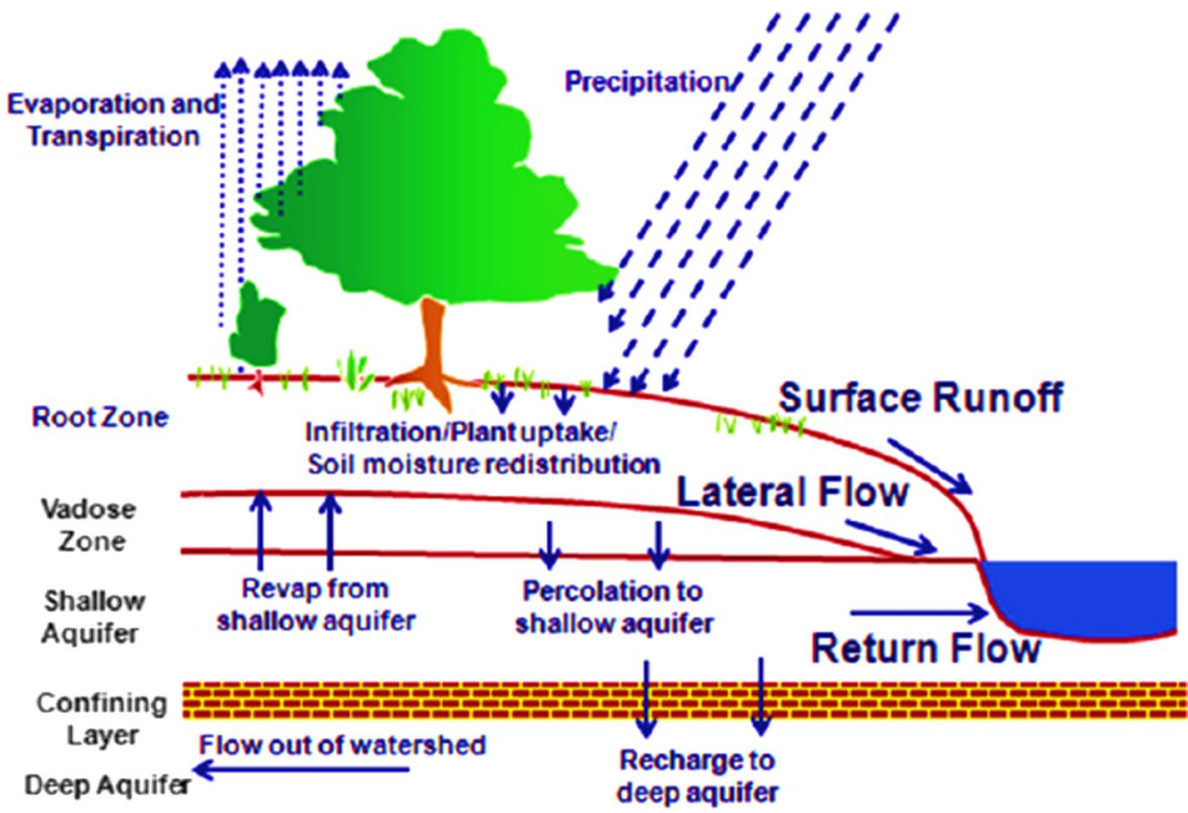

spatial unit of the model, hydrologic response units (HRUs) which is a unique combination of topography, soil type, and land use/land cover assuming there is no interaction between HRUs; Where, each one of HRUs is processing spatially uniform (non-spatially distributed) in terms of topography, soil type, land cover, and climate variables for routing of flow. Subsequently, the runoff is predicted independently for each one of HRUs, and then the results are aggregated to subbasin outlets based upon the HRUs fractions, and lastly routing subbasin outlets through a river reach within the channel network to obtain the overall runoff and sediment yield for the watershed. This will raise the efficiency of the model and gives a much better physical characterization of the water balance of the watershed as in Neitsch et al. (2011) and Arnold et al. (1998). Likewise, the SWAT model predicts the snowfall and melt, and vadose zone processes including evaporation, infiltration, lateral flow, percolation, plant uptake, and ground water flow as in Neitsch et al. (2011).

\section{Methodology}

\section{Creation of model data base}

The behavior of the SWAT model to represent the physical characteristics of any river catchment is related to the quality and the quantity of data that the SWAT model is fed up with. Subsequently, modelling in SWAT needs to database that represents the relief of a surface or digital elevation model (DEM), land use and land cover (LULC), soil properties, precipitation in daily details, solar radiation, maximum and minimum air temperature, wind speed, and relative humidity. These input databases are used to evaluate the runoff property and related parameters for the hydrological simulation of monthly stream flow in Hemren dam reservoir catchment, Fig. 3.

The ArcSWAT interface employs the DEM for delineation of stream networks, subbasins and delineates the catchment boundary by applying fundamental raster functions provided by ArcGIS along with its spatial analyst extension. In addition, the derived hydrology extension for delineation of streams from a raster DEM is used to calculate the subbasin parameters, such as the longest stream path distance and the topography of subbasin as in Di Luzio et al. (2004).

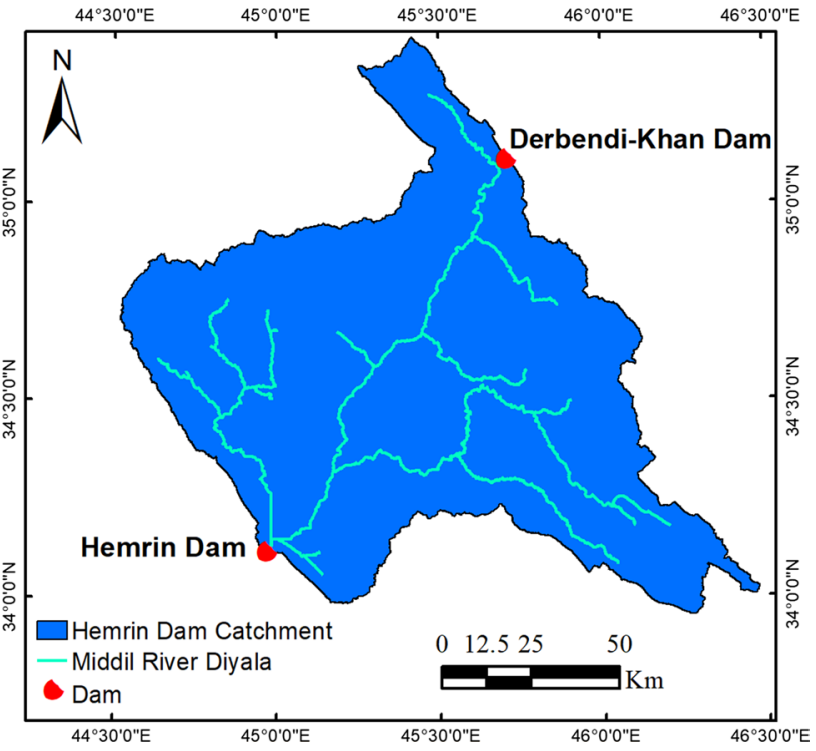

Fig. 3 Hemren dam reservoir catchment area beyond Derbendi-Khan dam.(SRTM 1_arc-second) 


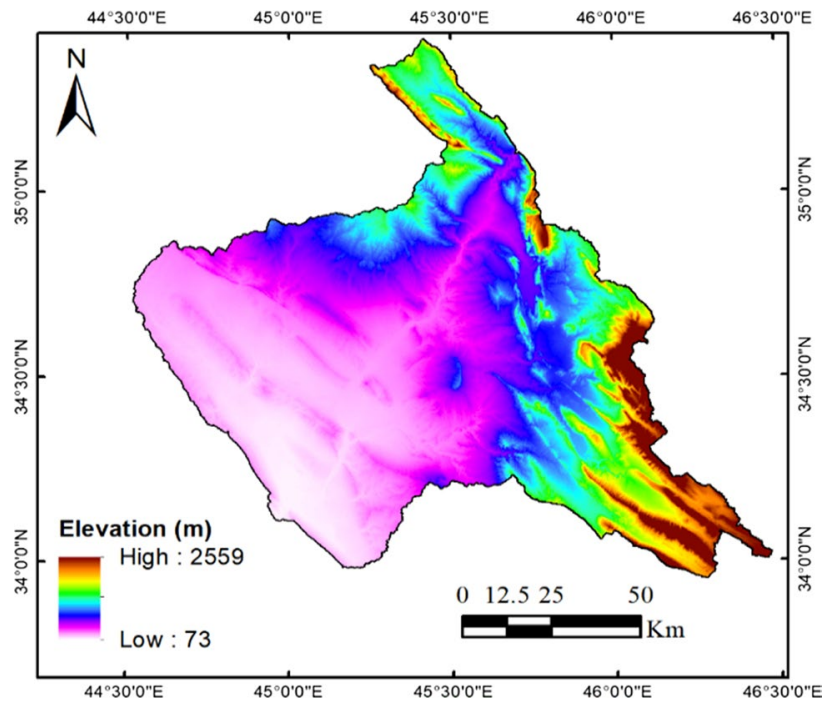

Fig. 4 Digital elevation model of Hemren dam reservoir catchment

The DEM has been used in this study and is approximate with a spatial resolution of $30 \mathrm{~m}$ by $30 \mathrm{~m}$ (1 arc-second) SRTM DEM Version 3.0, as shown in Fig. 4. The SRTM DEM found by NASA obtained from The Land Processes Distributed Active Archive Center (LP-DAAC) which is responsible for the archive and distribution of the NASA Making Earth System Data Records for Use in Research Environments (MEaSUREs) version SRTM and given in the website (https://earthexplorer.usgs.gov), in (.tif) ESRI format with geographic projection, WGS84 datum. Data were downloaded during January 2018 and projected into UTM coordinate system.

Soil classification map of the study area was made based on the global soil dataset of Food and Agriculture Organization of the United Nations (FAO-UNESCO soil) as in Food and Agriculture Organization of the United Nations and Land and Water Development Division (2003) soil classification system, which is outfit data for more than 5000 types of soil at a spatial scale of 1:5 million. Various hydrological processes in watershed modelling depend importantly on soil type. In the FAO-UNESCO soil, various soil properties are given as soil texture, available water content, bulk density, organic carbon content, and hydraulic conductivity. While these properties required to be analyzed to make an input in the ArcSWAT model for simulation purpose. Based on the soil classification, it was observed that the soils in the watershed were loam, clay loam, and clay soils (Fig. 5) and falls in the hydrologic soil group D. The coverage areas of various soil categories in the studied catchment and the input database codes in ArcSWAT are presented in Table 1.

Land use and cover (LU and LC) have critical effects for SWAT model input database while runoff and surface erosion affected with the land surface condition during rainfall

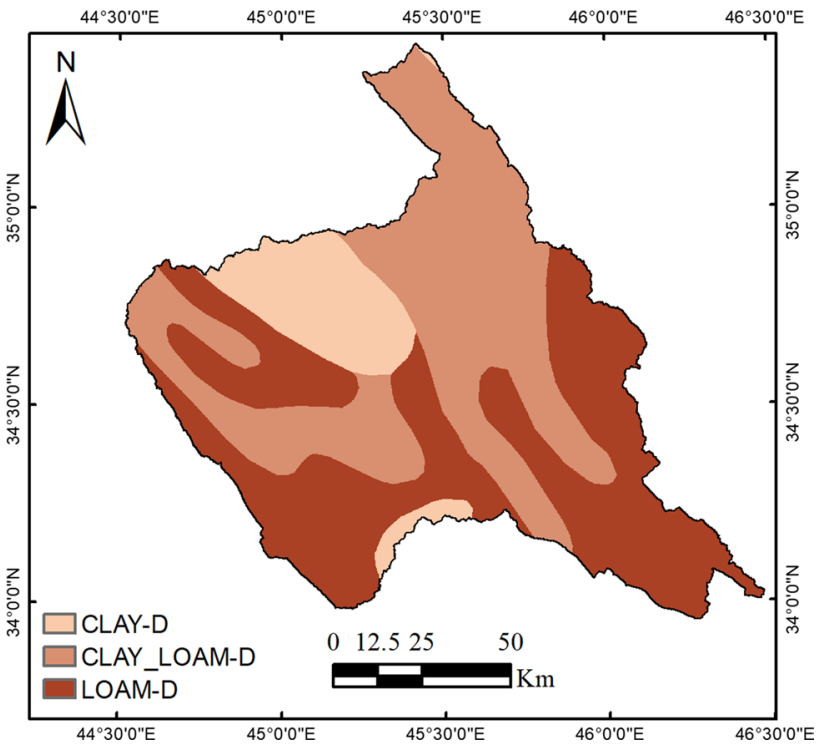

Fig. 5 Soil type and hydrological group of Hemren dam reservoir catchment

events. In the present study, the unsupervised classification method was used for preparation of the land use map. The LU and LC maps were prepared using remote sensing data of The Global Land Cover Characterization (GLCC) which consists of string of global LC classification data sets that depend on primarily unsupervised classification of $1.0 \mathrm{~km}$ Advanced Very High-Resolution Radiometer (AVHRR) 10-day Normalized Difference Vegetation Index (NDVI) composites. Since the modelling period conducted with SWAT has been extended from 1981 to 2008, a comparison of LU and LC was made from the earliest available land cover data which was in 1992 to the last year of simulation in the model 2008. Results show that there is no significant LU and LC change in the studied watershed during this period, where the percent value of change is $3.31 \%$ from the overall area of the catchment and distributed in different subbasins as presented in Fig. 6. Subsequently, the LU and LC maps of the year 2000 were used in SWAT model that shows the LU and LC applied in the SWAT model for Hemren dam catchment. In 2000, the coverage areas of several of the LU and LC categories in the studied catchment and the input database codes in ArcSWAT are presented in Table 2. The generic agricultural and barren lands are the two main types of LU and LC in the catchment, Fig. 7.

The land slope is the main gravidity driving force for overland flow. Subsequently, the HRUs generation was developed based on four classes of land slope categories, i.e., from 0 to $10 \%, 10$ to $20 \%, 20$ to $35 \%$, and above $40 \%$. The average values of land slope in the studied catchment area were $12.26 \%$. Figure 8 illustrates the representation of the land slope map of the catchment area. After the 
Table 1 Coverage areas of various soil categories in the Hemren dam catchment area

\begin{tabular}{lllcc}
\hline Soil type & Code in ArcSWAT & $\begin{array}{l}\text { Hydrologic } \\
\text { group }\end{array}$ & Area $\left(\mathrm{km}^{2}\right)$ & \% Watershed area \\
\hline LOAM & I-Rc-Xk-c-3122 & D & 2833.0 & 21.91 \\
LOAM & Rc33-3bc-3254 & D & 4.1 & 0.03 \\
CLAY & Vc1-3a-3276 & D & 9.5 & 0.07 \\
CLAY_LOAM & Xk28-b-3300 & D & 2786.3 & 21.55 \\
CLAY_LOAM & Xk5-3ab-3304 & D & 1101.5 & 8.52 \\
CLAY_LOAM & Xk9-2-3a-3312 & D & 1625.9 & 12.57 \\
LOAM & Yk34-b-3603 & D & 3001.0 & 23.21 \\
CLAY & Yy10-2-3a-3324 & D & 1568.7 & 12.13 \\
\hline
\end{tabular}
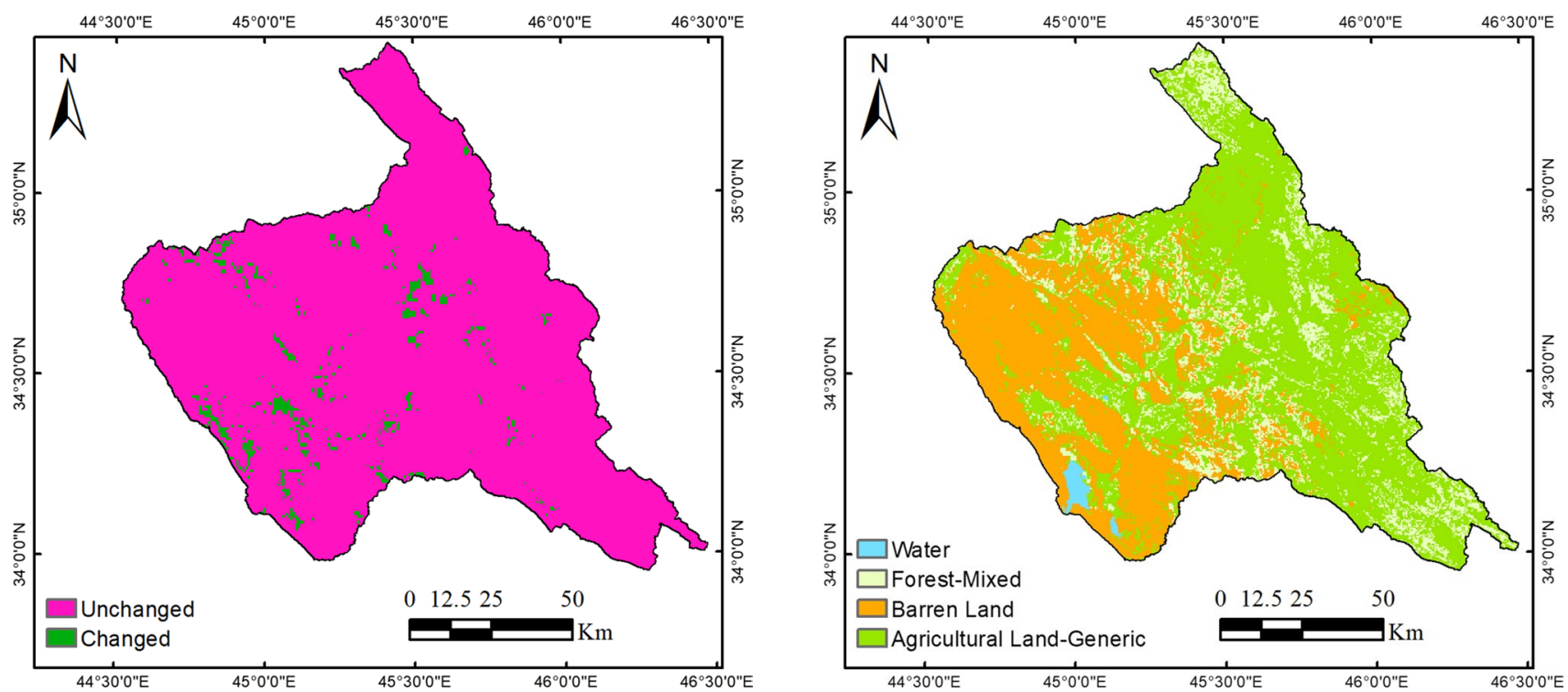

Fig. 6 Land cover/use change in Hemren dam reservoir catchment during 1992-2008

Table 2 Coverage areas of various land use/cover categories in the Hemren dam catchment area

\begin{tabular}{llrr}
\hline Land use category & Code in ArcSWAT & Area $\left(\mathrm{km}^{2}\right)$ & $\begin{array}{l}\% \text { age of } \\
\text { watershed } \\
\text { area }\end{array}$ \\
\hline $\begin{array}{l}\text { Agricultural land- } \\
\text { generic }\end{array}$ & AGRL & 6830.62 & 52.827 \\
Barren land & BARR & 4158.86 & 32.164 \\
Forester-mixed & FRST & 1847.33 & 14.287 \\
Water & WATER & 93.36 & 0.722 \\
\hline
\end{tabular}

creation of LU LC, soil classification, and the HRUs were analyzed by overlapping the unique spatial datasets of LU and LC, land slope and soil map. The values of threshold which adopted to create the HRUs were assigned as $0 \%$ for all spatial datasets land use, slope, and soil subsequently and then the HRUs have been generated all across the 33 subbasins of the area under study was 1035 .

Fig. 7 Land cover/use of Hemren dam reservoir catchment

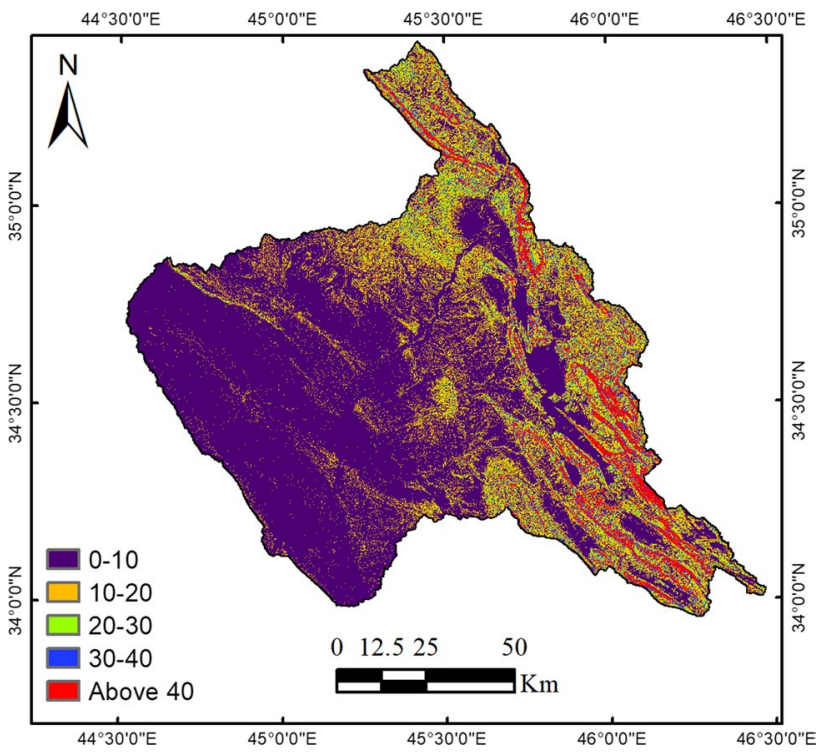

Fig. 8 Land slope of Hemren dam reservoir catchment 
Meteorological variables informations are the main thrust for any model of hydrological water balance. These variables include the precipitation, air temperature, wind speed, relative humidity, and solar radiation. Modelling in SWAT requires the daily climate information which can be feed to the model either from the measured data or from the generated data by using a weather generator model especially in data scars areas but after confirmation of the validity of the data by statistical evaluation (Mhaina 2017). At least, the SWAT model needs (requires) the daily data of precipitation and the maximum and minimum air temperature for transform the rainfall to runoff, where the others climate variables like solar radiation, wind speed, and humidity are derived using the weather generator model.

The daily measured meteorological variables data scarcity in this study was the main hindrance to build SWAT model for studied catchment, where the daily data availability for a long time period continuously and the density of weather stations do not give the reality of measurement distribution homogeneously of meteorological variables in catchments. To solve this problem with an acceptable guide, the available monthly averaged measured precipitation data for Khanaqin gauge station in the Hemren dam catchment are statistically assessed (tested) with the climate forecast system reanalysis (CFSR) of global weather station which is a satellite derived weather forecasting data produced by the National Centers for Environmental Prediction (NCEP) as in Global weather (2018). CFSR provides weather stations in $34 \mathrm{~km}$ horizontal resolution approximately, and data from sixteen stations were used in the resent study as shown in Fig. 9. The statistical values of coefficient of determination $\left(R^{2}\right)$, Nash-Sutcliffe efficiency $\left(E_{\mathrm{NS}}\right)$, and root-mean-square error (RMSE) were employed to judge whether both datasets belong to the same distribution or not. Results have shown that the values of $R^{2}, E_{\mathrm{NS}}$, and RMSE for the monthly comparison were equal to $0.80,0.59$, and 21.93 , respectively. These values are within the acceptable ranges, Fig. 10.

\section{Model setup}

Initially, the required database has been arranged for the studied area (Hemren dam catchment in the River Diyala downstream of Derbendi-Khan dam) then the model has set up to establish hydrological simulation for the area under observation. The model setup was done under the following steps: setup of SWAT project, automatic delineation of watershed, land use, soil properties, and topography definition then analysis of HRUs, metrological data definition then write input tables, editing input information; input the releases of Derbendi-Khan dam as a point source discharge at upstream of the watershed, SWAT simulation; run SWAT model, and read outputs. The methodology flowchart Fig. 11

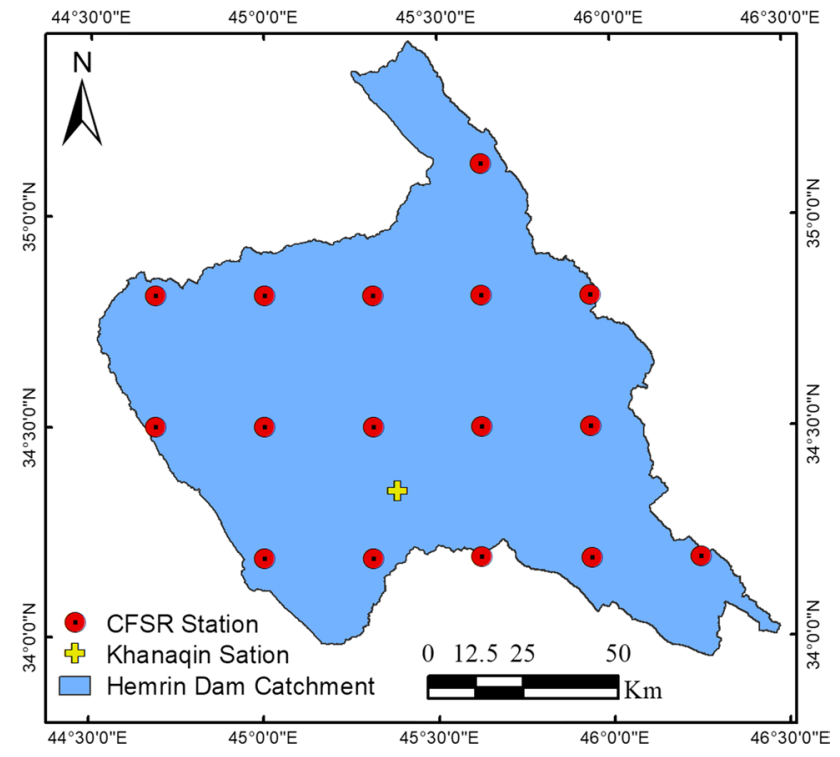

Fig. 9 Positions of CFSR and Khanaqin weather stations in the Hemren dam reservoir catchment

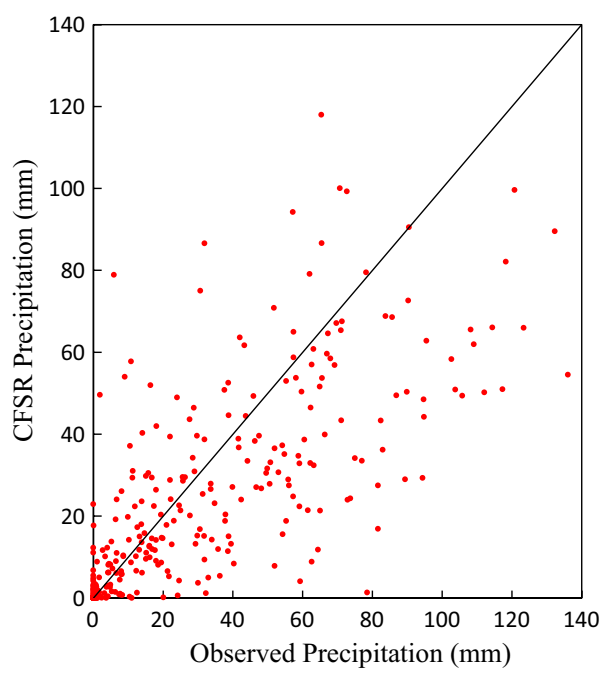

Fig. 10 Comparison of monthly observed and CFSR precipitation

gives a detail of these steps. To extract Hemren dam catchment at first, ArcSWAT 2012 automatically delineated the River Diyala watershed on the basis of DEM and the river's exhaust arrangement. The upstream and downstream boundaries of Hemren dam catchment determined by positioning the Derbendi-Khan dam site as inlet of draining watershed point and Hemren dam site defined as whole watershed outlet point. Subsequently, the SRTM DEM has been clipped with respect to the resultant clear Hemren dam catchment shape file to obtain DEM of Hemren dam catchment separately and then it was introduced in the model features.

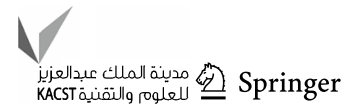


Fig. 11 Methodological framework adopted for SWAT Model of Hemren dam reservoir catchment area

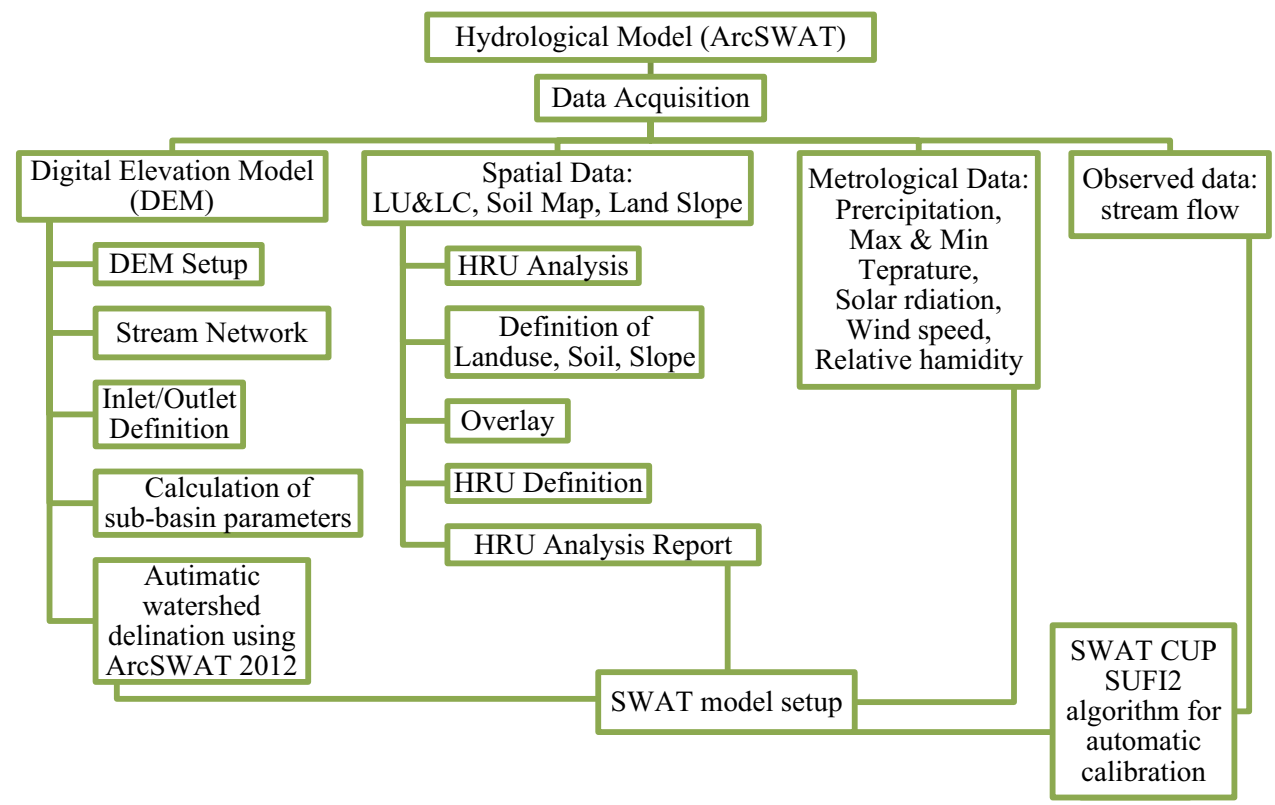

The DEM has to be pre-processed for the determination of the number and size of subbasins based on the threshold area 10,000 ha. The number of subbasins was thirty-three subbasins, and the areas of these subbasins ranged between 903 and 104,038 ha, Fig. 12. After delineation of the watershed and subbasins boundaries, a specific outlet for the study area has defined at Hemren dam site to generate the whole watershed. Also, the Derbendi-Khan dam station has been considered as a source point for the study area. Finally, the
SWAT model was run to simulate the various hydrological components with default parameters.

\section{Performance evaluation of the model}

Evaluation of the model performance was done by comparing the model runoff simulated value with the observed discharge data. Moriasi et al. (2007) suggested three statistical criteria to assess model performance which are used

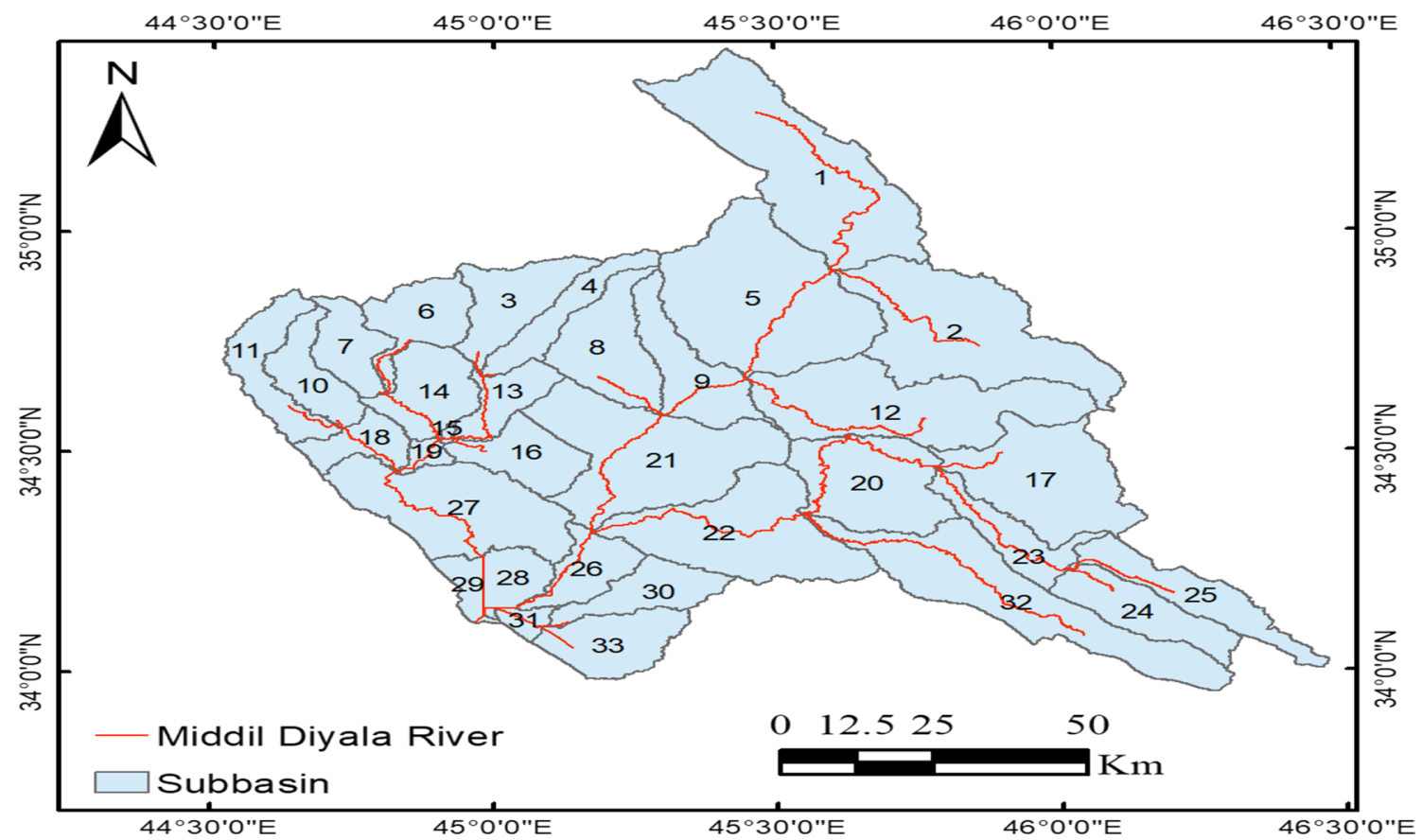

Fig. 12 SWAT-DEM delineated subbasins of Hemren dam reservoir catchment 
to evaluate the performance of the SWAT model simulation of the studied watershed: the Nash-Sutcliffe efficiency $\left(E_{\mathrm{NS}}\right)$ (Eq. 2), the ratio of root-mean-square error (RMSE) to the standard deviation of observed data $\left(S T D E V_{\text {obs }}\right)$, (RSR) (Eq. 3), and the percent bias ( $\left.P_{\text {bias }}\right)$ (Eq. 4), additionally the coefficient of determination $\left(R^{2}\right)$ (Eq. 5)was used for performance evaluation of the model.

Nash-Sutcliffe efficiency quantifies the variance of observed versus simulated data relative to a 1:1 best fit line; $E_{\mathrm{NS}}$ values range between $-\infty$ and 1 , where any $E_{\mathrm{NS}}$ value greater or equal to zero indicated that the simulated value estimated the constituent of concern better than the mean observed value and an $E_{\mathrm{NS}}$ value of one is a perfect simulation. The $E_{\mathrm{NS}}$ values were calculated using the following equation:

$E_{\mathrm{NS}}=1-\frac{\sum_{i=1}^{n}\left(O_{i}-S_{i}\right)^{2}}{\sum_{i=1}^{n}\left(O_{i}-\bar{O}\right)^{2}}$

where $O_{i}$ and $S_{i}$ are the simulated and observed discharge values, respectively, for the $i$ th pair of discharge values, $\bar{O}$ is the mean value of the observed discharge values, and $n$ is the total number of paired discharge values.

The ratio of root-mean-square error to the standard deviation is an error index statistic. Where, a perfect simulation will get if the values of RSR equal to zero and any RSR value less than 0.50 indicated an acceptable simulation. The RSR values were calculated using the following equation:

$\mathrm{RSR}=\frac{\mathrm{RMSE}}{\operatorname{STDEV}_{\mathrm{obs}}}=\frac{\sqrt{\sum_{i=1}^{n}\left(O_{i}-S_{i}\right)^{2}}}{\sqrt{\sum_{i=1}^{n}\left(O_{i}-\bar{O}\right)^{2}}}$

Percent bias test gives an indication about the average tendency of the simulated data to be greater than or less than the observed data. Where any negative $P_{\text {bias }}$ value indicates that the simulated data are greater than the observed data on average. On the contrary, any positive $P_{\text {bias }}$ value indicates that the simulated data is less than the observed data on average. A perfect simulation will get if the $P_{\text {bias }}$ is equal to zero. The $P_{\text {bias }}$ values were calculated using the following equation:
$P_{\text {bias }}=\frac{\sum_{i=1}^{n}\left(O_{i}-S_{i}\right)}{\sum_{i=1}^{n} O_{i}} \times 100$

A general performance statistical ratings of monthly stream flow time step of watershed model simulation results were recommended as in Moriasi et al. (2007) for the above three statistical criteria as given in Table 3 .

Additionally, the coefficient of determination $R^{2}$ used for assessing the simulation results correlation with the observed discharges. The $R^{2}$ describes the proportion of the variance between the measured data and that explained by the model. Ranges of $R^{2}$ extend between 0 and 1, with higher values indicating an improved accuracy of the simulation, and typically values greater than 0.5 are considered acceptable as in Santhi et al. (2001) and Van Liew et al. (2003). Although $R^{2}$ have been widely used for model evaluation, this statistic is oversensitive to outliers and insensitive to additive and proportional differences between model predictions and measured data as in Legates and McCabe (1999). The $R^{2}$ values were calculated using the following equation:

$R^{2}=\frac{\left[\sum_{i=1}^{n}\left(O_{i}-\bar{O}\right)\left(S_{i}-\bar{S}\right)\right]^{2}}{\sum_{i=1}^{n}\left(O_{i}-\bar{O}\right)^{2} \sum_{i=1}^{n}\left(S_{i}-\bar{S}\right)^{2}}$

where $\bar{S}$ is the mean value of the simulated discharge.

\section{Results and discussion}

\section{Sensitivity analysis of model parameters}

The Hemren dam catchment in ArcSWAT model has been initially executed with default parameters, and a variety of results has been generated, and in light of these results, automatically calibration done with an explicit interface software SWAT Calibration and Uncertainty Program (SWAT-CUP) which is specially developed for calibration and uncertainty analysis can be coupled with the SWAT model in which the factors for the representation can be selected in accordance with the objectives of the study. The SWAT-CUP package software which includes five calibration programs was
Table 3 General performance ratings for recommended statistics

\begin{tabular}{lllc}
\hline Performance rating & $E_{\mathrm{NS}}$ & RSR & $P_{\text {bias }}(\%)$ \\
\hline Very good & $0.75<E_{\mathrm{NS}} \leq 1.00$ & $0.00 \leq \mathrm{RSR} \leq 0.50$ & $P_{\text {bias }}< \pm 10$ \\
Good & $0.65<E_{\mathrm{NS}} \leq 0.75$ & $0.50<\mathrm{RSR} \leq 0.60$ & $\pm 10 \leq P_{\text {bias }}$ \\
& & & $< \pm 15$ \\
Satisfactory & $0.50<E_{\mathrm{NS}} \leq 0.65$ & $0.60<\mathrm{RSR} \leq 0.70$ & $\pm 15 \leq P_{\text {bias }}$ \\
& & & $< \pm 25$ \\
Unsatisfactory & $E_{\mathrm{NS}} \leq 0.50$ & RSR $>70$ & $P_{\text {bias }} \geq \pm 25$ \\
\hline
\end{tabular}


created by Eawag, Swiss Federal Institute that looks into prediction ambiguity of this parent SWAT model. In the resent study, the Sequential Uncertainty Fitting version 2 (SUFI2) algorithm developed as in Abbaspour et al. (2004, 2007) was used for calibration of the model and sensitivity analysis, and it is a multisite and semi-automated global search procedure. The sensitivity analysis for twenty-three hydrological parameters related to runoff was conducted to distinguish the sensitive parameters for model calibration as shown in Table 4 . The sensitivity analysis method that implemented in SWAT model is a Latin hypercube global sensitivity. Statistical $t$ test is used to identify the relative significance of each parameter; the larger value of $t$ stat in absolute value is the more sensitive parameter. The details of the method can be found in the SWAT-CUP user manual as in Abbaspour (2015).
In order to find the most sensitive parameters, three iterations with 500 simulations for each iteration was run, the result of sensitivity analysis during model calibration using the SUFI2 algorithm is ranked the parameters from the most to the least sensitive. Based on this ranking, seven parameters found to be mostly sensitive parameters for the studied catchment area were chosen for calibration. Based on the $t$ test and the p-value of the parameters, the global sensitivity assessment was dealt with for runoff measurement based on p-value and t test as presented in Table 4. These seven parameters appeared a highly sensitive level to model calibration with changes of parameter values that fitted during the two-iteration process. While other parameters were not seen to have as much of a significant effect on the runoff of the catchment simulation, where the relative modification in model input parameters also resulted in no considerable change in the outputs. The final maximum and minimum

Table 4 Sensitivity rank and uncertainties range of the model parameters based on SUFI2 algorithm for runoff calibration on monthly basis

\begin{tabular}{|c|c|c|c|c|c|c|c|}
\hline Rank & Parameter name & $t$ stat & $P$-value & Initial range & Calibrated range & Fitted value & Definition \\
\hline 1 & V_ALPHA_BF.gw & 16.47 & 0.00 & {$[0.05 ; 0.5]$} & {$[0.189 ; 0.467]$} & 0.299 & Baseflow alpha factor \\
\hline 2 & V_CH_K2.rte & -15.94 & 0.00 & {$[1 ; 150]$} & {$[1 ; 76.186]$} & 2.128 & $\begin{array}{l}\text { Effective hydraulic conductivity in main } \\
\text { channel alluvium }\end{array}$ \\
\hline 3 & R_CN2.mgt & -5.15 & 0.00 & {$[-0.4 ; 0.4]$} & {$[-0.636 ; 0.055]$} & -0.071 & SCS runoff curve number factor \\
\hline 4 & V_CH_N2.rte & -3.65 & 0.00 & {$[0.1 ; 0.3]$} & {$[0.191 ; 0.374]$} & 0.317 & Manning's " $n$ " value for the main channel \\
\hline 5 & R_SOL_AWC(..).sol & 2.65 & 0.01 & {$[-0.4 ; 0.4]$} & {$[-0.004 ; 0.787]$} & 0.269 & Available water capacity of the soil layer \\
\hline 6 & V_REVAPMN.gw & -2.05 & 0.04 & {$[0 ; 10]$} & {$[-3.606 ; 5.466]$} & 2.753 & $\begin{array}{l}\text { Threshold depth of water in the shallow } \\
\text { aquifer for "revap" to occur (mm) }\end{array}$ \\
\hline 7 & V_GW_REVAP.gw & 1.64 & 0.10 & {$[0.02 ; 0.2]$} & {$[0.106 ; 0.279]$} & 0.222 & Groundwater "revap" coefficient \\
\hline 8 & V_SFTMP.bsn & -1.57 & 0.12 & {$[-5 ; 5]$} & {$[-2.816 ; 2.396]$} & -1.883 & [OPTINAL] snowfall temperature \\
\hline 9 & R_SOL_BD(..).sol & 1.38 & 0.17 & {$[-0.02 ; 0.35]$} & {$[0.102 ; 0.347]$} & 0.252 & Soil moist bulk density \\
\hline 10 & V_PCPD(..).wgn & -1.35 & 0.18 & {$[0 ; 31]$} & {$[-7.459 ; 18.185]$} & 13.851 & $\begin{array}{l}\text { Average number of days of precipitation in } \\
\text { month }\end{array}$ \\
\hline 11 & V_SMFMX.bsn & 1.22 & 0.22 & {$[3 ; 7]$} & {$[2.974 ; 5.658]$} & 5.076 & $\begin{array}{l}\text { Maximum melt rate for snow during year } \\
\text { (occurs on summer solstice) }\end{array}$ \\
\hline 12 & V_SURLAG.bsn & 1.16 & 0.25 & {$[0.1 ; 12]$} & {$[1.307 ; 8.437]$} & 6.034 & Surface runoff lag time \\
\hline 13 & V_SMFMN.bsn & 1.04 & 0.30 & {$[0 ; 5]$} & {$[0.867 ; 3.623]$} & 2.871 & $\begin{array}{l}\text { Minimum melt rate for snow during the year } \\
\text { (occurs on winter solstice) }\end{array}$ \\
\hline 14 & V_GW_DELAY.gw & -0.99 & 0.32 & {$[30 ; 400]$} & {$[-25.721 ; 258.141]$} & 124.442 & Groundwater delay \\
\hline 15 & R_SLSUBBSN.hru & -0.72 & 0.47 & {$[-0.4 ; 0.4]$} & {$[-0.451 ; 0.116]$} & 0.052 & Average slope length \\
\hline 16 & R_OV_N.hru & 0.65 & 0.52 & {$[-0.3 ; 0.3]$} & {$[-0.324 ; 0.092]$} & -0.051 & Manning's " $n$ " value for overland flow \\
\hline 17 & V_GWQMN.gw & -0.61 & 0.54 & {$[30 ; 100]$} & {$[62.158 ; 126.502]$} & 70.330 & $\begin{array}{l}\text { Threshold depth of water in the shallow } \\
\text { aquifer required for return flow to occur } \\
(\mathrm{mm})\end{array}$ \\
\hline 18 & V_RCHRG_DP.gw & -0.58 & 0.56 & {$[0 ; 1]$} & {$[0.315 ; 0.947]$} & 0.675 & Deep aquifer percolation fraction \\
\hline 19 & R_PCPMM(..).wgn & -0.54 & 0.59 & {$[-0.1 ; 0.2]$} & {$[-0.044 ; 0.119]$} & 0.042 & $\begin{array}{l}\text { Average amount of precipitation falling in } \\
\text { month }[\mathrm{mm} / \mathrm{dd}]\end{array}$ \\
\hline 20 & R_SOL_K(..).sol & 0.50 & 0.62 & {$[-0.1 ; 0.3]$} & {$[-0.257 ; 0.114]$} & 0.075 & Saturated hydraulic conductivity \\
\hline 21 & V_SMTMP.bsn & 0.27 & 0.79 & {$[-3 ; 3]$} & {$[-0.892 ; 3.328]$} & 1.062 & Snow melt base temperature \\
\hline 22 & V_ESCO.hru & 0.12 & 0.90 & {$[0.1 ; 0.95]$} & {$[0 ; 0.606]$} & 0.044 & Soil evaporation compensation factor \\
\hline 23 & V_EPCO.hru & -0.09 & 0.93 & {$[0.01 ; 1]$} & {$[0.434 ; 1.283]$} & 0.505 & Plant uptake compensation factor \\
\hline
\end{tabular}

$\mathrm{V}_{-}$means the existing parameter value is to be replaced by a given value, and $\mathrm{R}_{-}$means an existing parameter value is multiplied by $(1+\mathrm{a}$ given value). (..)means for different soil layers or months 


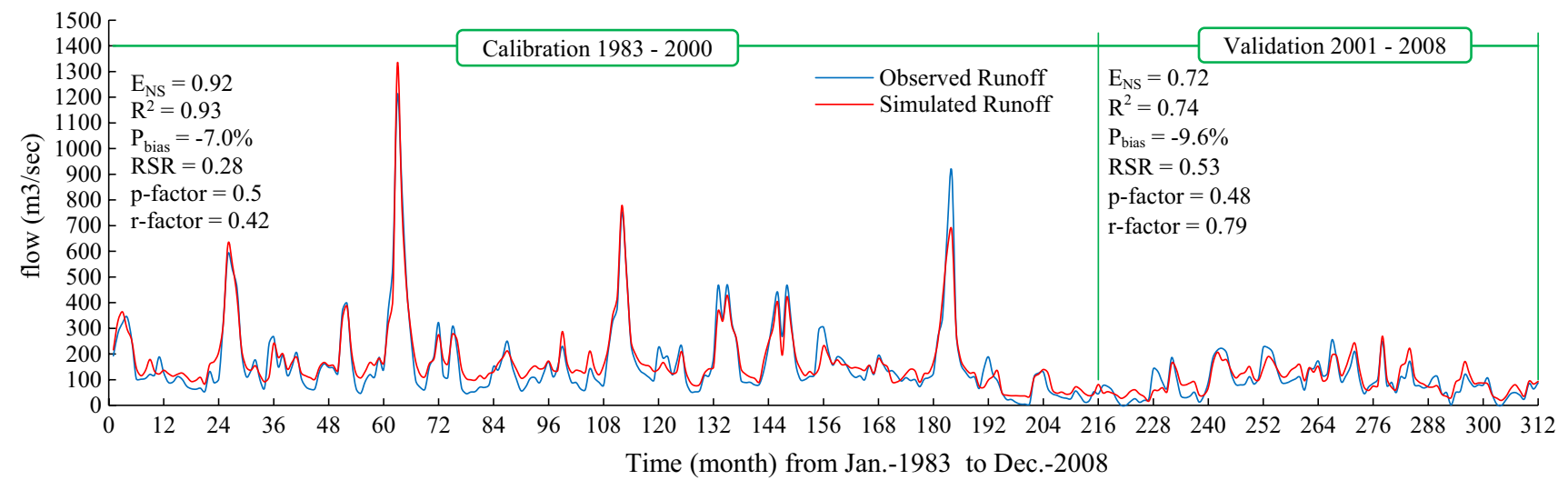

Fig. 13 Monthly observed and simulated runoff at the Hemren dam reservoir for the period 1983-2008

along with fitted standards of the consideration for monthly calibration using SUFI2 techniques are presented in Table 4.

\section{Results and evaluation of model calibration and validation}

The SWAT model was calibrated and validated based on the monthly observed stream discharges data that are recorded at the outlet of the studied watershed (Hemren dam reservoir) during a period extended for a twenty-eight year between 1981 and 2008. From this, 2-year records (1981-1982) were kept as a warm-up period, and the remaining time interval was used to model calibration, i.e., 1983-2000 as well as for model validation, i.e., 2001-2008. The model calibration period was from January 1983 to December 2000. The sensitivity analysis of parameters and choosing the calibrated range of parameters is given in Table 4. While the third iteration with 500 simulations runs was applied to achieve the model calibration. Subsequently, validation of the model was conducted through iteration with the same numbers of simulations (500) of the final calibrated model parameters range (Table 4) from January 2001 to December 2008. Results of the simulated monthly runoff for the calibration and validation periods were plotted in time series with observed stream flow for visual comparison to explore the similarity between the observed and simulated values of runoff as presented in Fig. 13. From Fig. 13, it can be seen that the model forecasts of monthly discharge almost have a similar trend to that of observed discharge values for both calibration and validation periods. Furthermore, it can be observed in general that the model gives good estimation of the peak values of runoff at all flood events during the years of calibration and was the percent error in peak discharge (PEP) (for peaks that greater than of average annual peaks $329.92 \mathrm{~m}^{3} / \mathrm{s}$ ) computed by dividing the difference between the simulated and observed peak discharges by the observed peak discharge as presented in Table 5. The correlation between monthly simulated and observed discharge
Table 5 The percent error in peak discharges (PEP)

\begin{tabular}{lclc}
\hline Date & Observed peak & Simulated peak & PEP $(\%)$ \\
\hline Apr-1983 & 344 & 364.2 & 5.9 \\
Feb-1985 & 587 & 626.4 & 6.7 \\
Apr-1987 & 397 & 386.3 & 2.7 \\
Mar-1988 & 1209 & 1331 & 10.1 \\
Apr-1992 & 751 & 778.1 & 3.6 \\
Mar-1994 & 470 & 428.6 & 8.8 \\
Apr-1995 & 468 & 421.9 & 9.9 \\
Apr-1998 & 910 & 681.6 & 25.1 \\
\hline
\end{tabular}

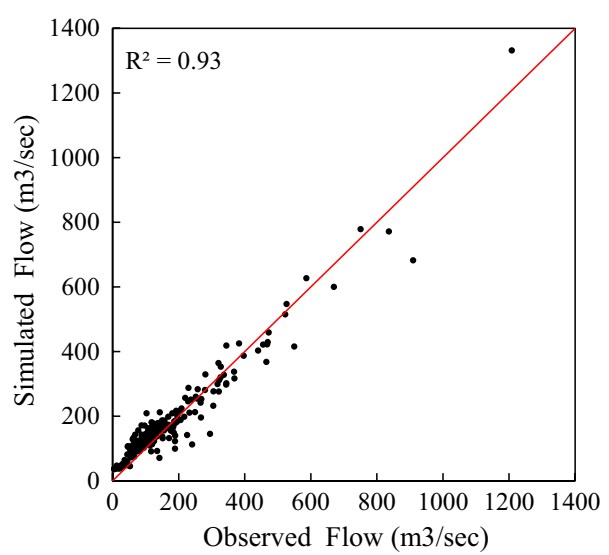

Fig. 14 Correlation between monthly observed and simulated stream flow measured during calibration (1983-2000)

is shown in Figs. 14 and 15 during calibration and validation periods. The suggested statistical model evaluation parameters that are given as in Moriasi et al. (2007), i.e., $E_{\mathrm{NS}}, P_{\text {bias }}$, and RSR and additionally $R^{2}$ have been computed for both calibration and validation periods which are represented in Table 6 . With these values, the model performance for the calibration period can be judged based on general performance ratings

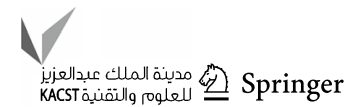




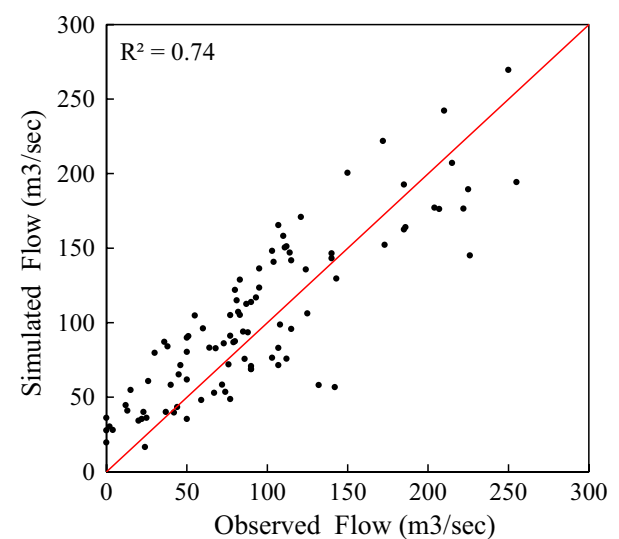

Fig. 15 Correlation between monthly observed and simulated. Stream flow measured during validation (2001-2008)

Table 6 Evaluation of SWAT model performance on monthly time basis

\begin{tabular}{lllll}
\hline Model stage & \multicolumn{4}{l}{ Evaluation statistics } \\
\cline { 2 - 5 } & $E_{\mathrm{NS}}$ & RSR & $P_{\text {bias }}(\%)$ & $R^{2}$ \\
\hline Calibration (1983-2000) & 0.92 & 0.28 & -7.0 & 0.93 \\
Validation (2001-2008) & 0.72 & 0.53 & -9.6 & 0.74 \\
\hline
\end{tabular}

given in Table 3 as very good quality according to all evaluation statistics. While the model performance ratings for the validation period is good based on $E_{\mathrm{NS}}, \mathrm{RSR}$, and $R^{2}$ and very good according to $P_{\text {bias }}$. Despite the change that happened in the trend of observed discharge due to the climatic changes especially during the validation period, the SWAT model simulation result is sty dependable. Also, the total annual runoff volume in BCM was computed for the simulated and observed runoff as presented in Fig. 16, and results shown that the statistical evaluation parameters $E_{\mathrm{NS}}, P_{\text {bias }}$, RSR, and $R^{2}$ values were $0.93,-6.95 \%, 0.26$, and 0.98 , respectively. The average annual inflow volume for the observed and simulated calculated values was 4.562 BCM, 5.00 BCM, respectively. Furthermore, the water balance components were calculated with primary and calibrated SWAT model parameters based on Eq. (1) for the twenty-eight years of simulation with two warm-up years; the calculated outcomes of water balance ratios have been given in the Check tool of the software on hydrology window and detailed in Table 7. Subsequently, the net runoff without the inlet source from Derbendi-Khan dam reservoir at upstream of the catchment area has been calculated by running SWAT model for twenty-eight year by replacing the parameters in SWAT model project database files to the best fitted parameter values of the last iteration resulted by SWAT-CUP calibration. Results show that an effective runoff happens at wet seasons, and there is not continuous effective base flow from the catchment area, Fig. 17, and the average annual inflow volume to Hemren dam reservoir during the period $1983-2008$ was $0.871 \mathrm{BCM}$. This represents $17.42 \%$ of the overall inflow volume (Hemren dam reservoir catchment and release from Derbendi-Khan dam reservoir) to Hemren dam reservoir. The time series and the annual volume of flow interring to Hemren dam reservoir is presented in Fig. 18, and this amount of inflow is significant value due to water scarcity in the present dry subsequently seasons. Also, the average spatial contributions of runoff volume according to subbasins were calculated, and results showed that the runoff volume ranged between $0.2 \mathrm{MCM}$ and $186 \mathrm{MCM}$ as illustrated in

Table 7 SWAT model simulation of water balance ratios

\begin{tabular}{lll}
\hline Ratio details & $\begin{array}{l}\text { Primary simula- } \\
\text { tion }\end{array}$ & $\begin{array}{l}\text { Calibrated } \\
\text { simulation }\end{array}$ \\
\hline Stream flow/precipitation & 0.32 & 0.18 \\
Base flow/total flow & 0.05 & 0.52 \\
Surface runoff/total flow & 0.95 & 0.48 \\
Percolation/precipitation & 0.04 & 0.02 \\
Deep recharge/precipitation & 0.00 & 0.01 \\
ET/precipitation & 0.68 & 0.84 \\
\hline
\end{tabular}

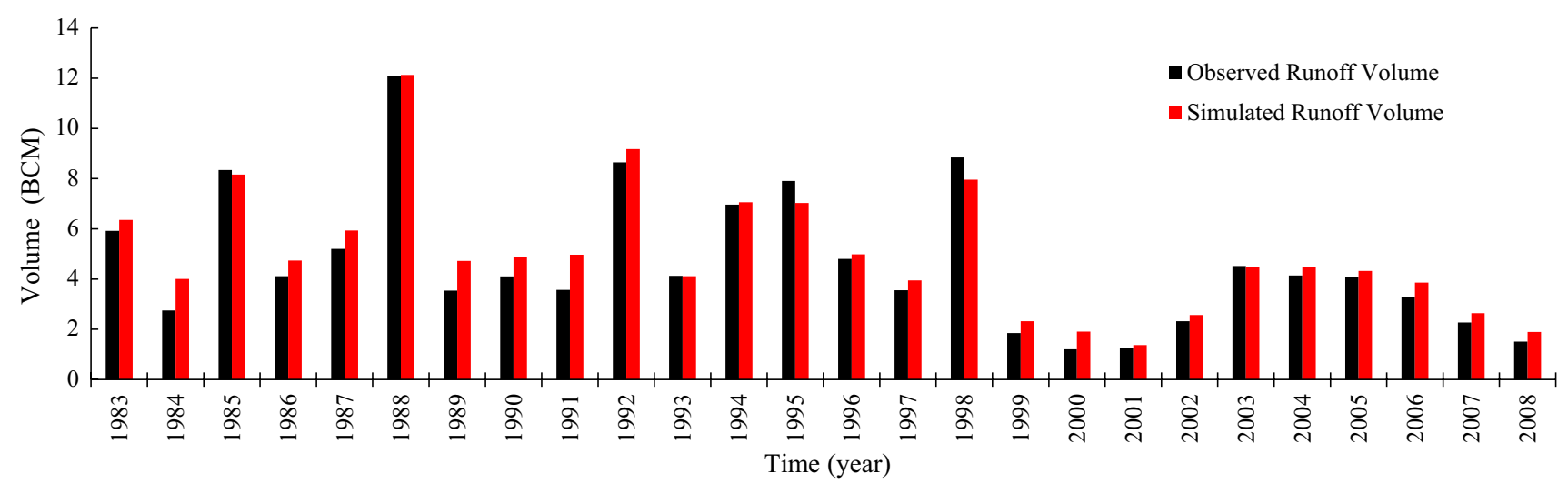

Fig. 16 Annual runoff volume delivered to the Hemren dam reservoir for the period 1983-2008 


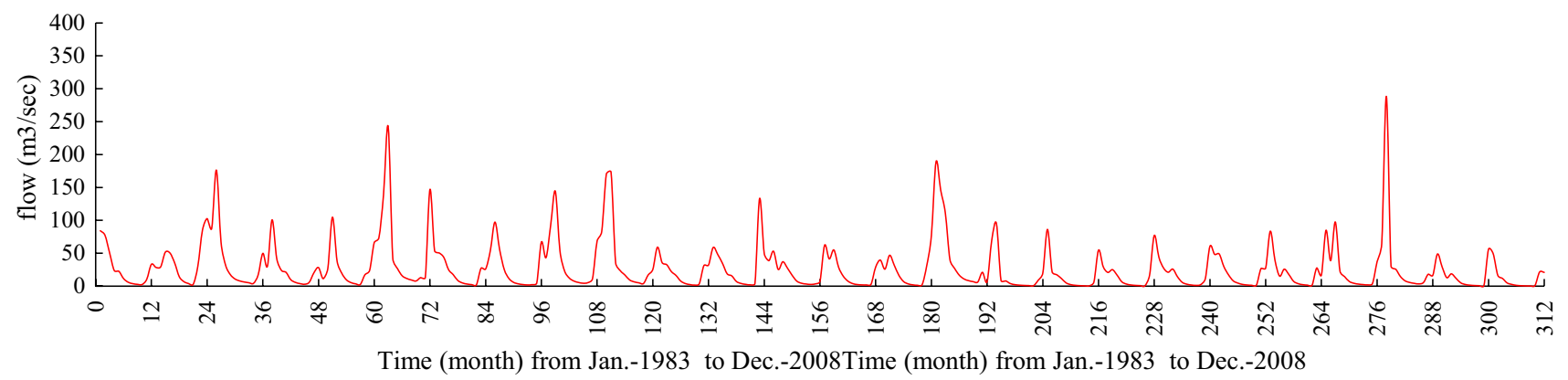

Fig. 17 Monthly simulated runoff contribution by Hemren dam reservoir catchment area for the period 1983-2008

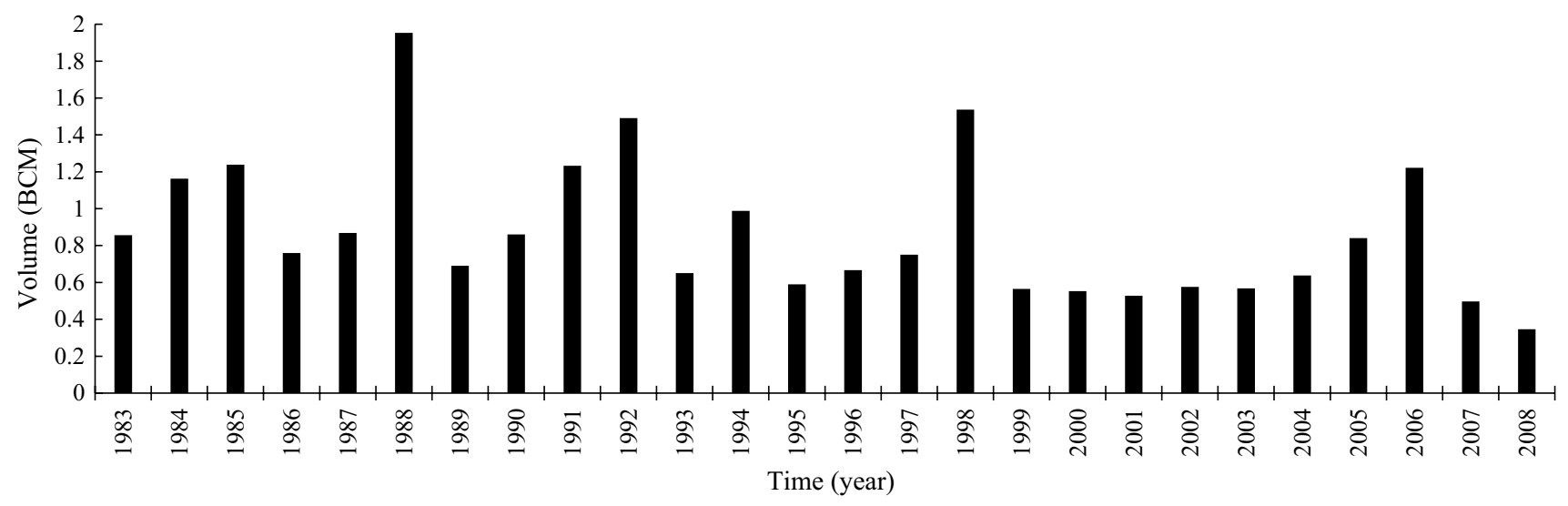

Fig. 18 Annual runoff volume contributed by Hemren dam reservoir catchment area for the period 1983-2008

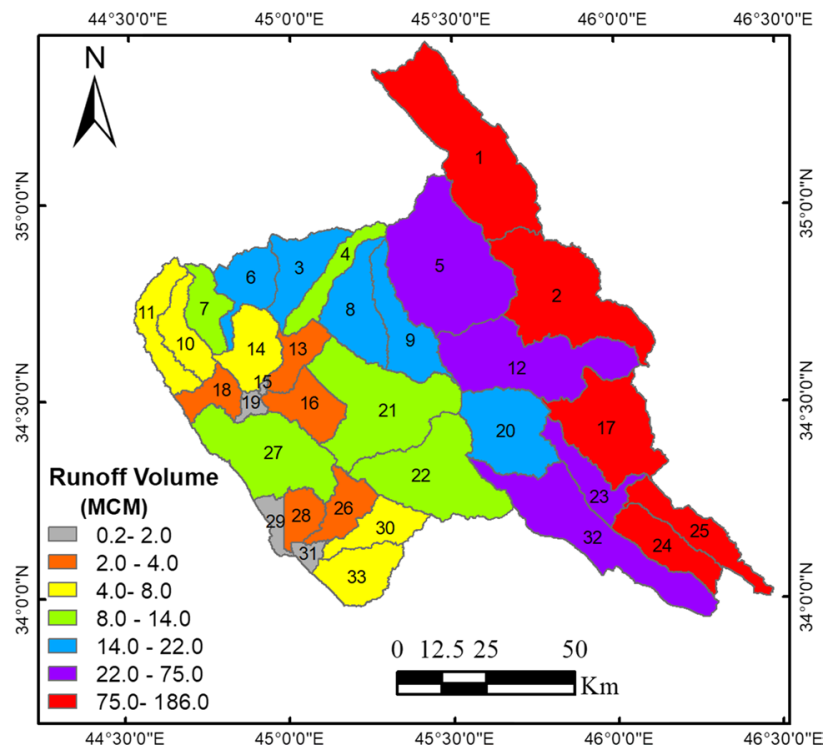

Fig. 19 Average spatially runoff volume in MCM contributed by subbasins for the period 1983-2008
Fig. 19. In this study, results show that the evapotranspiration is the main process that causes very high percent $(84 \%)$ of precipitation to be lost from the surface although the soils in the catchment were three statistical criteria mostly loamy soils that hinder deep percolation losses. Finally, a simple direct regression formula is determined by correlating the monthly runoff volume with monthly rainfall depth based upon the results of calibrated ArcSWAT model of the studied catchment area. The resultant relationship is given as the following form:

$V_{\text {ro }}=1.498 \times P_{m}^{1.194}-18.401$

where $V_{\text {ro }}$ is the monthly runoff volume in MCM and $P_{m}$ is the monthly precipitation depth in $\mathrm{mm}$. The $R^{2}$ values of this relationship were 0.695 and accepted for $P_{m}>8.173 \mathrm{~mm}$.

\section{Conclusions}

In this study, ArcSWAT 2012, a physical-based semidistributed hydrological model having an interface with ArcView GIS software, was applied to Hemren dam catchment at the middle Diyala River reach, which is a semi-arid basin. Hydrological prediction is needed to be an effective model calibration for an effective output. The 
model reproduced runoff that inputs to the dam reservoir by determining the optimal values of the hydrological model parameters based on the observed stream flow data at the Hemren dam reservoir site. The model was built with a threshold value 10,000 ha, and then the thirty-three subbasins were produced included 1035 HRUs which were distributed in these subbasins, depending on the spatial data (LU and LC map, Soil type, and Slope map). The CFSR meteorological data sets on a daily basis at sixteen different stations were used as input data to run the model, where the statistical assessment between monthly observed precipitation data at Khanaqin gauge station and the CFSR shown that the values of $R^{2}, E_{\mathrm{NS}}$, and RMSE were equal to $0.80,0.59$, and 21.93 , respectively. Derbendi-Khan dam release was considered as an inlet, and Hemren dam site was defined as an outlet. The SWAT model simulated runoff was compared with the observed discharge data at Hemren dam site. For this study, the model was calibrated and validated for monthly stream flow using the observed data for a twenty-eight year between 1981 and 2008 of datasets. Out of these twenty-eight years, the model setup has been arranged the first 2 years were taken as warm-up period for model initialization (1981-1982) and 18 years (1983-2000) were used for calibration and rest of the years (2001-2008) for model validation, respectively. The stream flow parameters by using SWAT-CUP software were calibrated and based on the global sensitivity analysis the variation between the parameter ranges indicated and then identified the most sensitive parameters for the studied catchment area. Seven most sensitive parameters were found for the intermodal part of the Hemren dam catchment (ALPHA_BF.gw, CH_K2.rte, CN2.mgt, $\mathrm{CH}_{-}$ N2.rte, SOL_AWC(..).sol, REVAPMN.gw, GW_REVAP. $\mathrm{gw})$. For monthly time step simulation, the values of statistical evaluation parameters $E_{\mathrm{NS}}, \mathrm{RSR}, P_{\text {bias }}$, and $R^{2}$ were $0.92,0.28,-7.0 \%$, and 0.93 , respectively for the time of calibration. While for the time of validation, values were $0.72,0.53,-9.6 \%$, and 0.74 , respectively. These statistical values signify a good indicator of the high reliability of model performance. The runoff from the catchment is very much effected by evapotranspiration were $84 \%$ of precipitation lost. The spatially distribution of average runoff volume from subbasins indicated that subbasins 1, 2, 25, $17,24,32,5,12$, and 23 are the most effective subbasins that contribute $79 \%$ of runoff volume from the studied catchment area.

\section{Compliance with ethical standards}

Conflict of interest The authors declare that they have no conflict of interest.
Open Access This article is distributed under the terms of the Creative Commons Attribution 4.0 International License (http://creativeco mmons.org/licenses/by/4.0/), which permits unrestricted use, distribution, and reproduction in any medium, provided you give appropriate credit to the original author(s) and the source, provide a link to the Creative Commons license, and indicate if changes were made.

\section{References}

Abbaspour KC (2015) SWAT Calibration and uncertainty programs - A user manual. Swiss Fedral Institute of Aquatic Science and Technology

Abbaspour KC, Johnson CA, Van Genuchten MT (2004) Estimating uncertain flow and transport parameters using a sequential uncertainty fitting procedure. Vadose Zone J 3(4):1340-1352

Abbaspour KC et al (2007) Modelling hydrology and water quality in the pre-alpine/alpine Thur watershed using SWAT. J Hydrol 333(2-4):413-430

Al-Ansari NA, Al-Sinawi GT, Jamil AK (1986) Suspended and solute loads on the low Diyala river. IAHS-AISH Publ 159:225-235

Arnold JG, Srinivasan R, Muttiah RS, Williams JR (1998) Large area hydrologic modeling and assessment part I: model development 1. JAWRA 34(1):73-89

Arnold JG et al (2012) SWAT: model use, calibration, and validation. Trans ASABE 55(4):1491-1508

Baker TJ, Miller SN (2013) Using the Soil and Water Assessment Tool (SWAT) to assess land use impact on water resources in an East African watershed. J Hydrol 486:100-111

Boithias L, Sauvage S, Taghavi L, Merlina G, Probst JL, Pérez JMS (2011) Occurrence of metolachlor and trifluralin losses in the Save river agricultural catchment during floods. J Hazard Mater 196:210-219

Bouraoui F, Benabdallah S, Jrad A, Bidoglio G (2005) Application of the SWAT model on the Medjerda river basin (Tunisia). Phys Chem Earth Parts A B C 30(8-10):497-507

Chow VT, Maidment DR, Larry W (1988) Mays. Applied hydrology. MacGraw-Hill, Inc, New York, p 149

Di Luzio M, Srinivasan R, Arnold JG (2004) A GIS-coupled hydrological model system for the watershed assessment of agricultural nonpoint and point sources of pollution. Trans GIS 8(1):113-136

Elizabeth M (1994) Hydrology in practice, 3rd edn. Chapman \& Hall, London

Food and Agriculture Organization of the United Nations and Land and Water Development Division (2003) Digital soil map of the world and derived soil properties. FAO, Land and Water Development Division

Gassman PW, Sadeghi AM, Srinivasan R (2014) Applications of the SWAT model special section: overview and insights. J Environ Qual 43(1):1-8

Ghoraba SM (2015) Hydrological modeling of the Simly Dam watershed (Pakistan) using GIS and SWAT model. Alex Eng J 54(3):583-594

Globalweather (2018) NCEP climate forecast system reanalysis (CFRS). http://globalweather.tamu.edu/. Accessed Jan 2018

Jajarmizadeh M, Harun S, Salarpour M (2013) An assessment on base and peak flows using a physically-based model. Res J Environ Earth Sci 5(2):49-57

Legates DR, McCabe GJ (1999) Evaluating the use of "goodness-offit" measures in hydrologic and hydroclimatic model validation. Water Resour Res 35(1):233-241 
Mhaina AS (2017) Modeling suspended sediment load using SWAT model in data scarce area-Iraq (Al-Adhaim Watershed as a Case Study). M.Sc. Thesis, University of Technology (unpublished)

Molina-Navarro E, Trolle D, Martínez-Pérez S, Sastre-Merlín A, Jeppesen E (2014) Hydrological and water quality impact assessment of a Mediterranean limno-reservoir under climate change and land use management scenarios. J Hydrol 509:354-366

Moriasi DN, Arnold JG, Van Liew MW, Bingner RL, Harmel RD, Veith TL (2007) Model evaluation guidelines for systematic quantification of accuracy in watershed simulations. Trans ASABE 50(3):885-900

Moriasi DN, Steiner JL, Arnold JG (2011) Sediment measurement and transport modeling: impact of riparian and filter strip buffers. J Environ Qual 40(3):807-814

Neitsch SL, Arnold JG, Kiniry JR, Srinivasan R, Williams JR (2002) Soil and water assessment tool user's manual version 2000 . GSWRL report, 202(02-06)

Neitsch SL, Arnold JG, Kiniry JR, Williams JR (2011) Soil and water assessment tool theoretical documentation version 2009. Texas Water Resources Institute

Noori N, Kalin L (2016) Coupling SWAT and ANN models for enhanced daily streamflow prediction. J Hydrol 533:141-151

Oeurng C, Sauvage S, Sánchez-Pérez JM (2010) Temporal variability of nitrate transport through hydrological response during flood events within a large agricultural catchment in south-west France. Sci Total Environ 409(1):140-149

Santhi C, Arnold JG, Williams JR, Dugas WA, Srinivasan R, Hauck LM (2001) Validation of the swat model on a large rwer basin with point and nonpoint sources 1. JAWRA 37(5):1169-1188
Sellami H, Benabdallah S, La Jeunesse I, Vanclooster M (2016) Quantifying hydrological responses of small Mediterranean catchments under climate change projections. Sci Total Environ 543:924-936

Shivhare V, Goel MK, Singh CK (2014) Simulation of surface runoff for upper Tapi subcatchment Area (Burhanpur Watershed) using swat. Int Arch Photogram Remote Sens Spatial Inf Sci 40(8):391

Shrestha MK, Recknagel F, Frizenschaf J, Meyer W (2016) Assessing SWAT models based on single and multi-site calibration for the simulation of flow and nutrient loads in the semi-arid Onkaparinga catchment in South Australia. Agric Water Manag 175:61-71

Singh A, Gosain AK (2011) Climate-change impact assessment using GIS-based hydrological modelling. Water Int 36(3):386-397

Todini E (2007) Hydrological catchment modelling: past, present and future. Hydrol Earth Syst Sci 11(1):468-482

Van Liew MW, Arnold JG, Garbrecht JD (2003) Hydrologic simulation on agricultural watersheds: choosing between two models. Trans ASAE 46(6): 1539

Wang G, Xia J (2010) Improvement of SWAT2000 modelling to assess the impact of dams and sluices on streamflow in the Huai River basin of China. Hydrol Process Int J 24(11):1455-1471

Publisher's Note Springer Nature remains neutral with regard to jurisdictional claims in published maps and institutional affiliations. 